Research Article

\title{
Antimicrobial Activity of the Synthesized of Copper Chalcogenide Nanoparticles
}

\author{
N. G. Mbewana-Ntshanka $\mathbb{D}^{1}{ }^{1}$ M. J. Moloto $\mathbb{D}^{1},{ }^{1}$ and P. K. Mubiayi $\mathbb{D}^{2}$ \\ ${ }^{1}$ Department of Chemistry, Faculty of Applied and Computer Sciences, Vaal University of Technology, Private Bag X021, \\ Vanderbijlpark 1900 RSA, South Africa \\ ${ }^{2}$ School of Chemistry, University of the Witwatersrand, Private Bag 3, Johannesburg 2050 RSA, South Africa
}

Correspondence should be addressed to M. J. Moloto; molotmj@unisa.ac.za

Received 26 October 2020; Revised 18 January 2021; Accepted 8 March 2021; Published 18 March 2021

Academic Editor: Sumit Beniwal

Copyright (c) 2021 N. G. Mbewana-Ntshanka et al. This is an open access article distributed under the Creative Commons Attribution License, which permits unrestricted use, distribution, and reproduction in any medium, provided the original work is properly cited.

\begin{abstract}
Antimicrobial activity of copper chalcogenides nanoparticles was investigated by synthesizing copper selenide, copper sulfide, and copper oxide via the hot-injection method. Since reaction time has a profound effect on the nanocrystals size and shapes, the effect of reaction time was also investigated during the synthesis of the copper chalcogenides to obtain nanocrystals with desired properties. The reaction time showed no effect on the phase composition of the synthesized copper sulfide, copper oxide, and copper selenide nanoparticles. However, the size variation of nanoparticles with different reaction time was observed. Reaction time of 30 minutes gave the best optical (the shape of the absorption band edge and emission maxima values) and structural (size distribution of particles) properties for CuSe and $\mathrm{CuS}$ compared to other reaction times $(15,45$, and $60 \mathrm{~min})$. Their band edges were located at $506(2.45 \mathrm{eV})$ and $538 \mathrm{~nm}(2.30 \mathrm{eV})$, respectively. For this reaction time, copper selenide produced nanoparticles with a size range of 1-27 nm and copper sulfide nanoparticles ranged 1-18 nm. The morphologies of both chalcogenides at $30 \mathrm{~min}$ reaction time were spherical. Reaction time of 15 minutes gave the best optical and structural properties for copper oxide nanoparticles with a band edge of $454 \mathrm{~nm}(2.73 \mathrm{eV})$ and particle size ranging $0.8-3.2 \mathrm{~nm}$, but nonetheless, 30 min was used as the optimum reaction time for all three chalcogenides. The optimum parameter $\left(220^{\circ} \mathrm{C}, 30 \mathrm{~min}\right.$, and $\left.1: 1 \mathrm{ratio}\right)$ was used to synthesize the three copper chalcogenides which were then tested against Gram-negative (E. coli and P. aeruginosa), Gram-positive (S. aureus and E. faecalis), and fungi (C. albicans) employing both agar disk diffusion and minimum inhibitory concentration (MICs) methods. Copper oxide nanoparticles showed more sensitivity towards four bacterial microorganisms than the other two chalcogenides followed by copper sulfide nanoparticles with copper selenide nanoparticles being the least sensitive. The sensitivity of copper oxide nanoparticles is attributed to the smaller size of oxygen atom which strongly affects its reactivity and stability and hence very stable and highly reactive compared to sulfur and selenium.
\end{abstract}

\section{Introduction}

Copper chalcogenide nanoparticles are being sought in both fundamental science and technological applications [1]. Copper-based semiconductors have recently gained recognition as biocompatible alternatives due to bacterial infections which has become a concern globally mainly due to the development of antibiotic resistance. In the past years, there has been an increased resistance in Gram-negative bacteria [2]. The World Health Organization (WHO) estimated that approximately $80 \%$ of the population of the developing country rely on traditional medicines, mostly plants or derived products for disease treatment (WHO, 1993) [3].

Numerous therapeutic approaches are being used to control different diseases. A current approach is the development of new compounds such as nanoparticles. These nanoparticles will need to be in the right size range and adequate cell biocompatibility [4]. The reason for this is because the use of nanoparticles for biological-related applications is strongly affected by their sizes. In the colloidal method, the investigation of reaction time is the main feature for particle growth and size distribution in order to get nanocrystals with 
desired properties $[5,6]$. The availability of a large number of nuclei at a given time induces a decrease in the nanoparticle size; hence, many nuclei are preferred. Shorter nucleation time is better for control of size distribution [7]. Furthermore, the particles with smaller sizes dissolve and recrystallize because of their higher surface energy. This suggests that time has a profound effect on the nanocrystals size and shapes with longer time reaction favoring large particle size [8]. The size and the shape of particles are determined by the Ostwald ripening process [9]. The keypoint to accomplish the desired nanocrystals is to balance the nucleation and growth processes kinetically because the size distribution of initial nuclei may increase or decrease depending on the kinetics of the subsequent growth process. This may also prevent the formation of bulk crystals [10].

These nano-sized semiconductors have been synthesized by a variety of methods for tuning the properties for specific applications. As mentioned in the previous work reported by Mbewana-Ntshanka et al. [11], the methods that have been extensively used for the synthesis of the nano-sized semiconductors include precipitation methods [12], sol gel methods [13], solid-liquid discharge [14], electrochemical radiolysis alcohothermal [15], alcohothermal [16], direct thermal [17], sonochemical [18], microwave radiation [19], and colloidal-thermal methods [20]. Nevertheless, these methods are complicated and have disadvantages such as requiring drastic conditions, difficult control of particle growth, and higher energy consumption [20]. The colloidal hot-injection method which was employed in this work has been reported to produce nanocrystals with a narrow size distribution. This method allows you to control the conductive properties of the material by controlling the size of the crystals. It further gives a privilege of separating nucleation and growth stages during the synthesis resulting to high monodispersed material without having to do postsynthesis size-selective technique [21]. This method requires relatively high but not extreme temperatures. Under those conditions, particles with good crystalline structure are obtained and can relatively be isolated after a short time of synthesis.

The biological and medical research communities have exploited the unique properties of nanomaterials for various applications [22]. Semiconductor nanoparticles have been proven to have a wide range of potential biomedical applications, especially when combined with antigen specific coatings or functional groups on their surfaces [23]. The extremely high surface areas and unusual crystal morphologies endow copper oxide nanoparticles with antimicrobial activity. The dose dependently inhibits Escherichia coli strains but not Salmonella typhimurium [24]. This finding provides a way to develop a novel and specific antimicrobial agent such as copper chalcogenides nanoparticles. This study therefore attempts to explore the effect of reaction time during the synthesis of copper chalcogenides nanoparticles and their antimicrobial effect on selected microorganisms using both agar disk diffusion and minimum inhibitory concentration (MICs) methods. This work will also facilitate the exploration of copper chalcogenides nanoparticles against other pathogenic organisms.

\section{Materials and Methods}

2.1. Synthesis of Copper Selenide, Copper Sulfide, and Copper Oxide Nanoparticles. Oleylamine (OLA), copper (I) chloride, selenium powder, sulfur powder, urea solid, methanol (99.5\%), and acetone (99.8\%) were purchased from Sigma Aldrich. In this study, synthesis of copper oxide, copper sulfide, and copper selenide nanoparticles was approached by the colloidal hot-injection method. About $5 \mathrm{ml}$ of OLA was placed in a three-neck flask, equipped with a reflux condenser (waterless condenser) and a thermometer under a nitrogen atmosphere for both reactions. The content was heated to $120^{\circ} \mathrm{C}$ under nitrogen environment with a magnetic stirrer on it. About $330 \mathrm{mg}(0.0033 \mathrm{~mol})$ of copper chloride was dispersed into $3 \mathrm{ml}$ of OLA and injected into OLA that is in the three-neck flask via a syringe. The content was heated up to $220^{\circ} \mathrm{C}$, at which a solution of about $26.06 \mathrm{mg}(0.0033 \mathrm{~mol})$ of selenium (sulfur or urea) in $3 \mathrm{ml}$ of OLA was added via syringe. The content was heated at $220^{\circ} \mathrm{C}$ for about 30 minutes, followed by cooling to $80^{\circ} \mathrm{C}$, and then cleaning twice with ethanol and once with acetone via centrifugation at $5000 \mathrm{rev} / \mathrm{min}$ for $10 \mathrm{~min}$. The precipitate was left to dry for 24 hours at room temperature. The sample was dispersed into toluene, sonicated for 30 minutes, and then characterized using ultraviolet visible spectroscopy (UV-Vis), photoluminescence (PL), and transmission electron microscopy (TEM). The solid sample was further characterized with XRD.

2.2. Antimicrobial Study. The antimicrobial study of the synthesized nanoparticles was carried out by testing them against Gram-positive bacteria strains (Staphylococcus aureus and Enterococcus faecalis), Gram-negative bacteria strains (Escherichia coli and Pseudomonas aeruginosa), and fungal strain (Candida albicans). The disk diffusion method was first used to screen the antimicrobial activity; thereafter, the minimal inhibitory concentration (MIC) method was used, and neomycin was used as a negative control for antibacterial studies and amphotericin for antifungal studies.

2.2.1. Preparation and Test for the Agar Disk Diffusion Method. Stock cultures were maintained at $4^{\circ} \mathrm{C}$ on slopes of nutrient agar. Active cultures (Escherichia coli, Pseudomonas aeruginosa, Candida albicans, Staphylococcus aureus, and Enterococcus faecalis) for the experiment were prepared by transferring a loop full of cells from the stock cultures to a flask containing Muller-Hinton broth (MHB) and Muller-Hinton agar (MHA) and incubated for 24 hours at $37^{\circ} \mathrm{C}$.

Disk diffusion plates for the bacterial test were prepared by weighing $10 \mathrm{~g}$ of malt-extraction agar (MEA) into a $200 \mathrm{ml}$ flask, and $200 \mathrm{ml}$ of distilled water was added. The solute was dissolved using a microwave, autoclaved for 1 hour, and then cooled to room temperature. The plates were prepared by transferring about $15 \mathrm{ml}$ of a molten media into a sterile disk plates under sterilized fume hood. Disk diffusion plates for the fungal test were prepared the same way but 7.6 $\mathrm{g}$ of Muller-Hinton agar (MHA) was used instead of 
malt-extraction agar. The disk plates were left for 10 minutes to solidify. Inoculum suspension was swabbed uniformly and allowed to dry for 5 minutes. A well of $6 \mathrm{~mm}$ was created on a disk, and $50 \mu \mathrm{L}(0.06 \mathrm{mg} / \mathrm{L})$ of the sample was added. The sample was allowed to diffuse for 5 minutes and then incubated at $37^{\circ} \mathrm{C}$ for 24 hours. In general, antimicrobial agent diffuses into agar during the incubation period and inhibits germination and growth of the test microorganisms, and the diameter of their inhibition zones are measured.

2.2.2. MIC Test Method. Minimum inhibitory concentration (MIC) of the plant extracts' copper chalcogenides nanoparticles (copper selenide, copper sulfide, and copper oxide) was determined using the microdilution bioassay as described by Gupta [25]. Overnight cultures (incubated at $37^{\circ} \mathrm{C}$ ) of Escherichia coli, Pseudomonas aeruginosa, C. albicans, Staphylococcus aureus, Enterococcus faecalis, Klebsiella pneumoniae, and bacterial strains were each diluted with sterile Mueller-Hinton broth (MHB) to give final inoculum of approximately $1 \times 10^{6} \mathrm{CFU} / \mathrm{ml}$ (colony forming units). $60 \mathrm{mg}$ of copper chalcogenides nanoparticles were each dissolved in $3 \mathrm{ml}$ of $0.17 \%$ ethanol solution to make a concentration of $20.0 \mathrm{mg} / \mathrm{ml}$. One hundred (100) microliters of each solution were serially diluted to two-fold with sterile Mueller-Hinton broth in a 96-well microliter plate for each of the four bacterial strains. A two-fold dilution of neomycin $(20 \mathrm{mg} / \mathrm{ml})$ was used as positive control, and water was used as negative control. One hundred microliters of each bacterial culture were added to each well. Bacterial growth was indicated by adding $50 \mu \mathrm{l}$ of $0.02 \%$ resazurin. The plates were covered and incubated at $37^{\circ} \mathrm{C}$ for $24 \mathrm{hrs}$. Since the colorless tetrazolium salt is biologically reduced to a red product due to the presence of active organisms, the MIC values were determined as the concentration in the last wells with no color change observed. Bacterial growth in the wells was indicated by a reddish-pink color. The assay was repeated twice with two replicates per assay.

2.3. Characterization Techniques. The optical properties of the synthesized material were determined by dissolving the synthesized nanoparticles in a toluene and placing the content in a quartz cuvette $(1 \mathrm{~cm}$ path length). The absorbance measurements were recorded using a double beam Perkin Elmer lambda $25 \mathrm{UV} / \mathrm{Vis}$ spectroscopy with a wavelength range of $0-900 \mathrm{~nm}$. The emissions were measured using a single beam Jasco spectrofluorometer FP-8600 with XE lamp at $150 \mathrm{~W}$ operated at $200-1010 \mathrm{~nm}$. The morphology of the particles was determined by drop casting the particles that were dissolved in toluene to copper grids; then, images were taken using transmission electron microscopy (Technai $\mathrm{G}^{2} \mathrm{TEM}$ spirit) operated at $200 \mathrm{kV}$. The $\mathrm{X}$-ray diffraction patterns were determined using the Bruker D2 phase analyzer, XRD Beam knife $3 \mathrm{~mm}(5 \mathrm{~mm}$ is all the way up), and diffracted beam antiscatter slit $6.6 \mathrm{~mm}$. Fourier transform infrared analysis were recorded on a FTIR Perkin Elmer 400 spectrometer using a diamond detector.

\section{Results and Discussion}

3.1. Optical Properties of Copper Selenide, Copper Sulfide, and Copper Oxide Nanoparticles. Semiconductor crystalline are characterized by their band gap energy (Eg) that falls within the range $0<\mathrm{Eg}<4 \mathrm{eV}$ and can be thought of as the minimum energy required to excite an electron from the valence band to the conduction band [26]. Copper chalcogenides (Se, $\mathrm{S}$, and $\mathrm{O}$ ) displays different bulk band gaps and differ in their nanosize regime fundamentally based on their molecular sizes, ionization potentials, electronegativity, and electron affinity. The reaction times for the synthesis of oleylamine-capped copper selenide, copper sulfide, and copper oxide nanoparticles were investigated. Time was varied to $15,30,45$, and 60 minutes, while other parameters such as temperature $\left(220^{\circ} \mathrm{C}\right)$ and the concentration of the precursors (1:1 ratio) were kept constant. The UV/Vis absorption spectra of copper selenide, copper sulfide, and copper oxide nanoparticles synthesized at 15, 30, 45, and 60 minutes are shown in Figure 1. Table 1 provides the extracted optical parameters.

The absorption band edges of all copper selenide, copper sulfide, and copper oxide nanoparticles that were prepared at $15,30,45$, and 60 minutes were blue shifted from that of the bulk material band gap $(1180,1022$, and $1033 \mathrm{~nm})$ respectively. This blue shift results from quantum confinement effects [27]. The band edges of copper selenide nanoparticles were observed at $766,506,587$, and $674 \mathrm{~nm}$, respectively. The band edges of the synthesized copper sulfide nanoparticles were found at $678 \mathrm{~nm}, 538 \mathrm{~nm}, 585 \mathrm{~nm}$, and $598 \mathrm{~nm}$, respectively. The band edges of both copper selenide and copper sulfide nanoparticles that were synthesized at 30 minutes indicated a blue shift compared to other three materials prepared at 15, 45, and 60 minutes. This suggests that 30 minutes synthesis gave smaller particle size than all the other times investigated.

The absorption curves of these two materials are also different from the rest of the three materials, suggesting that the optical properties of this material would differ from the rest of the materials. Copper sulfide nanoparticles produced two different types of absorption curves predicting different optical properties. The materials prepared at times of 30 and 60 minutes resembled a chalcocite phase characteristic while $15 \mathrm{~min}$ and $45 \mathrm{~min}$ resembled covellite phase characteristics as predicted by Ravi et al. [28], Moloto et al. [29], and Cheon et al. [30] in their investigations. The band edge of the material synthesized for 15 minutes is red shifted from those of other materials that were synthesized for longer period time. This higher wavelength predicts bigger diameter of particles for the shortest time of 15 minutes. But when the reaction time was increased from 30 minutes to 45 and 60 minutes, the band edges increased to higher wavelength predicting an increase in particle size. This agrees with what was reported by Kalenga et al. [5] who observed particle size increment with reaction time through Ostwald ripening as presented in Table 2. The absorption band edges of copper oxide nanoparticles synthesized at $15,30,45$, and 60 minutes are observed at $454 \mathrm{~nm}, 457 \mathrm{~nm}, 460 \mathrm{~nm}$, and $574 \mathrm{~nm}$, respectively. UV-Vis spectra revealed that the absorption 

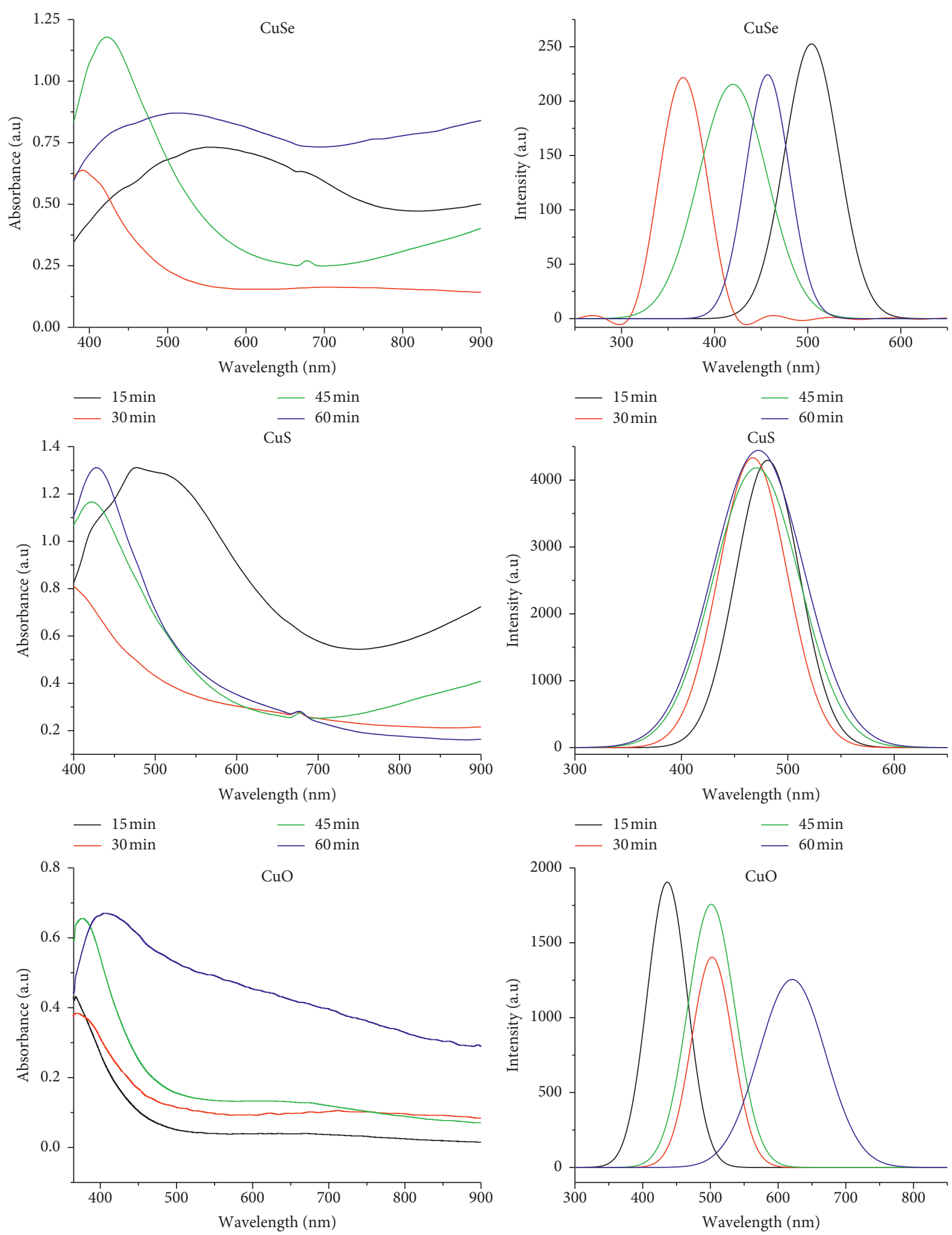

$-15 \mathrm{~min}$

$-45 \mathrm{~min}$

(a)

$15 \mathrm{~min}$
$-30 \mathrm{~min}$

$$
\begin{array}{r}
-45 \mathrm{~min} \\
-60 \mathrm{~min}
\end{array}
$$

(b)

FIGURE 1: (a) Absorption and (b) emission spectra of copper selenide, copper sulfide, and copper oxide nanoparticles synthesized for 15, 30, 45 , and $60 \mathrm{~min}$ in $\mathrm{OLA}$ at $220^{\circ} \mathrm{C}$ using $1: 1$ mole ratio. 
TABle 1: Optical parameters of copper selenide, copper sulfide, and copper oxide nanoparticles synthesized for 15, 30, 45, and 60 min.

\begin{tabular}{|c|c|c|c|c|c|c|c|c|c|}
\hline \multirow{3}{*}{ Time (min) } & \multicolumn{9}{|c|}{ Nanoparticles } \\
\hline & \multicolumn{3}{|c|}{$\mathrm{CuSe}$} & \multicolumn{3}{|c|}{$\mathrm{CuS}$} & \multicolumn{3}{|c|}{$\mathrm{CuO}$} \\
\hline & $\begin{array}{l}\text { Band edge } \\
(\mathrm{nm}: \mathrm{eV})\end{array}$ & $\begin{array}{l}\text { Emission } \\
\max (\mathrm{nm})\end{array}$ & FWHM (nm) & $\begin{array}{l}\text { Band edge } \\
\text { (nm: eV) }\end{array}$ & $\begin{array}{l}\text { Emission } \\
\max (\mathrm{nm})\end{array}$ & FWHM (nm) & $\begin{array}{c}\text { Band edge } \\
\text { (nm: eV) }\end{array}$ & $\begin{array}{l}\text { Emission } \\
\max (\mathrm{nm})\end{array}$ & FWHM (nm) \\
\hline 15 & $766(1.62)$ & 505 & 61 & $678(1.80)$ & 482 & 68 & $454(2.73)$ & 445 & 90 \\
\hline 30 & $506(2.45)$ & 365 & 55 & $538(2.30)$ & 468 & 72 & $457(2.71)$ & 502 & 69 \\
\hline 45 & $587(2.11)$ & 417 & 102 & $585(2.12)$ & 471 & 91 & $460(2.70)$ & 503 & 81 \\
\hline 60 & $674(1.84)$ & 457 & 53 & $598(2.07)$ & 482 & 95 & $574(2.16)$ & 622 & 116 \\
\hline
\end{tabular}

TABLE 2: Optical and physical properties of copper selenide, copper sulfide, and copper oxide nanoparticles synthesized for 30 min in comparison with previously reported data.

\begin{tabular}{|c|c|c|c|c|c|c|}
\hline & \multicolumn{6}{|c|}{ Nanoparticles } \\
\hline & \multicolumn{2}{|c|}{ CuSe } & \multicolumn{2}{|c|}{$\mathrm{CuS}$} & \multicolumn{2}{|c|}{$\mathrm{CuO}$} \\
\hline & Results obtained & Literature [31] & Results obtained & Literature [32] & Results obtained & Literature [33] \\
\hline $\begin{array}{l}\text { Optimum } \\
\text { conditions }\end{array}$ & $\begin{array}{l}30 \text { min and } \\
220^{\circ} \mathrm{C}\end{array}$ & $30 \mathrm{~min}$ and $220^{\circ} \mathrm{C}$ & $\begin{array}{l}30 \mathrm{~min} \text { and } \\
220^{\circ} \mathrm{C}\end{array}$ & $25 \mathrm{~min}$ and $0^{\circ} \mathrm{C}$ & $\begin{array}{l}30 \text { min and } \\
220^{\circ} \mathrm{C}\end{array}$ & $180 \mathrm{~min}$ and $400^{\circ} \mathrm{C}$ \\
\hline Band edge/band gap & $506 \mathrm{~nm}(2.45 \mathrm{eV})$ & $400 \mathrm{~nm}(3.1 \mathrm{eV})$ & $538 \mathrm{~nm}(2.3 \mathrm{eV})$ & $593 \mathrm{~nm}(2.09 \mathrm{eV})$ & $457 \mathrm{~nm}(2.71 \mathrm{eV})$ & - \\
\hline Particle size & $1-27 \mathrm{~nm}$ & $2-9 \mathrm{~nm}$ & $1-18 \mathrm{~nm}$ & $3-5 \mathrm{~nm}$ & $0.1-8 \mathrm{~nm}$ & $26-30 \mathrm{~nm}$ \\
\hline Particle shape & Spherical & Hexagonal & Spherical & $\begin{array}{l}\text { Undefined } \\
\text { clusters }\end{array}$ & Spherical & Spherical \\
\hline
\end{tabular}

bands tend to increase with the increase in reaction time. This agrees well with what has been reported in literature that prolonged time yields larger particle size due to the Ostwald ripening process [34]. The absorption bands predict that 15 min materials should have smallest particles while 60 min should have the biggest particles when four materials are compared.

The emission spectra of the three different materials are shown in Figure 1. Copper selenide nanoparticles produced their maximum intensity at 505, 365, 417, and $457 \mathrm{~nm}$, respectively, and for copper sulfide nanoparticles are located at 482, 468, 471, and $482 \mathrm{~nm}$, respectively, corresponding for $15,30,45$, and $60 \mathrm{~min}$ reaction intervals, respectively. The emission peaks of these materials corroborate their UV/Vis spectra by following the same trend as their absorption curve. In copper selenide, a broad peak for the material synthesized at 45 minutes is observed with a FWHM of $102 \mathrm{~nm}$, and this suggests that the material is polydispersed. The emission peak of the $15 \mathrm{~min}$ material is also broad and red shifted from other three materials and produced high intensity. This suggests that this material should have the biggest particle size as suggested by its absorption curve.

Narrow emission peaks for copper selenide were observed at 30 and 60 minutes with full width at half maximum of $55 \mathrm{~nm}$ and $53 \mathrm{~nm}$, respectively. Particles prepared at 15 and 45 minutes gave emission peaks with a full width at height maximum of 61 and $102 \mathrm{~nm}$ predicting less monodispersity. Copper sulfide nanoparticles showed similar trends to copper selenide, although copper selenide gave the largest FWHM value at 45 minutes. In contrast to the other materials, copper oxide gave the largest dispersity at 60 minutes with a FWHM of $116 \mathrm{~nm}$.
3.1.1. Morphology of the Synthesized Copper Selenide, Copper Sulfide, and Copper Oxide Nanoparticles. The morphology of the synthesized copper selenide, copper sulfide, and copper oxide nanoparticles was studied by TEM, and their images are given in Figure 2 together with their size distribution graphs. Some of the size distribution graphs are not displayed due to mixed morphologies of particles they produced. 15, 30, 45, and 60 minutes reaction times of copper sulfide produced particles in size range $(2-108 \mathrm{~nm})$, $(1-18 \mathrm{~nm}),(2-38 \mathrm{~nm})$, and $(5-58 \mathrm{~nm})$, respectively. 15 minutes reaction time in copper selenide produced particles that are highly agglomerated with no defined shapes, and this corroborates its corresponding emission peak that produced high intensity. TEM image of the particles synthesized at 15 minutes suggest that this reaction time was too short for a complete nucleation. Particles that were produced at 30 minutes are sphere-like structures with size ranging 1-27 nm. 45 and 60 minutes produced particles with size ranging $3-180 \mathrm{~nm}$ and $10-1200 \mathrm{~nm}$, respectively, that are mixed morphology. The sphere-like structures that were obtained in this work have been commonly reported in literature during the synthesis of copper chalcogenide nanoparticles as given in Table $2[31,33]$. When the time of the reaction of copper selenide was increased to 45 minutes, the spherical-like particles that were observed at $30 \mathrm{~min}$ transformed into hexagonal structure, truncated triangles, prisms, and cubes structures indicating a continuous growth of particles. This size and morphology evolution could be due to the Ostwald ripening process. Different particle sizes and particle shapes that are produced by material synthesized at 45 minutes are in good agreement with its FWHM that suggested a polydispersed material. When the reaction time was increased further to 60 minutes, the evolution of 


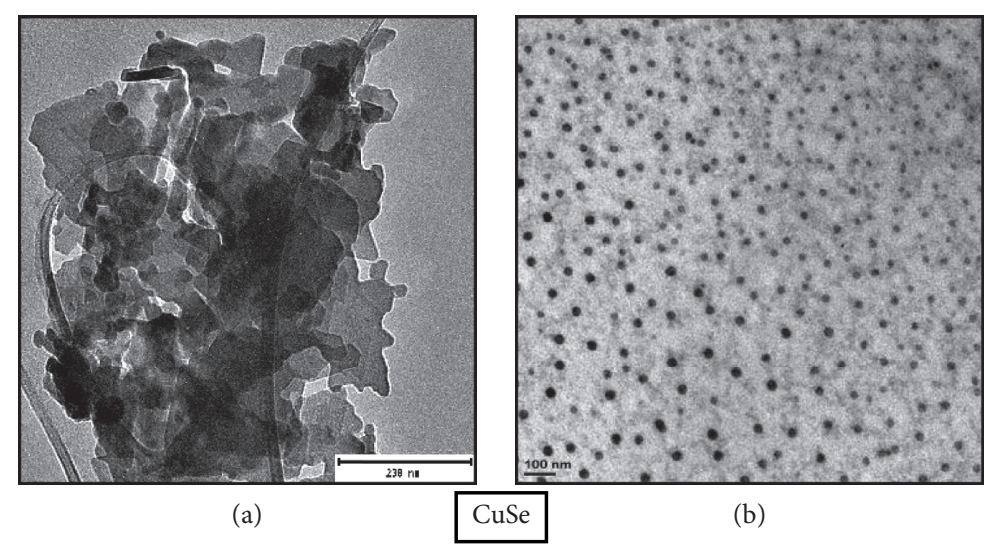

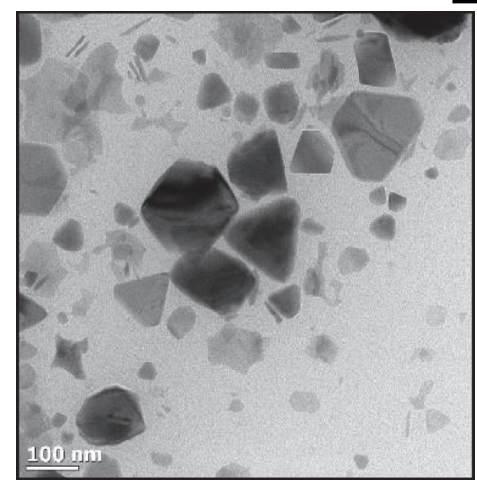

(c)

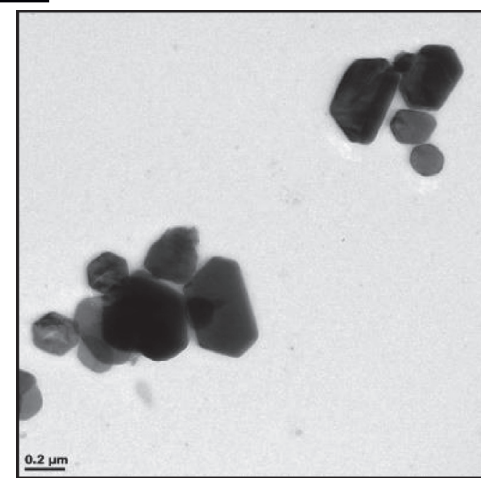

(d)

(a)

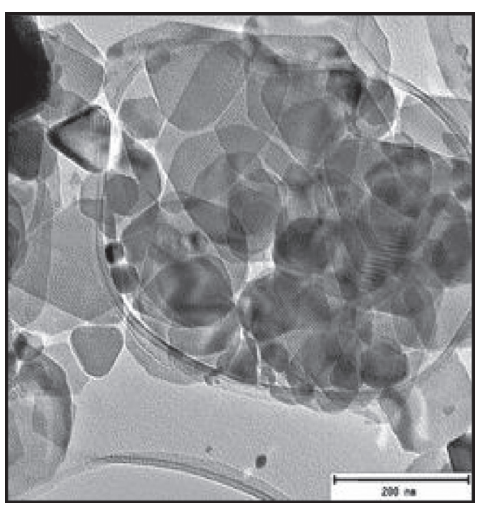

(a)

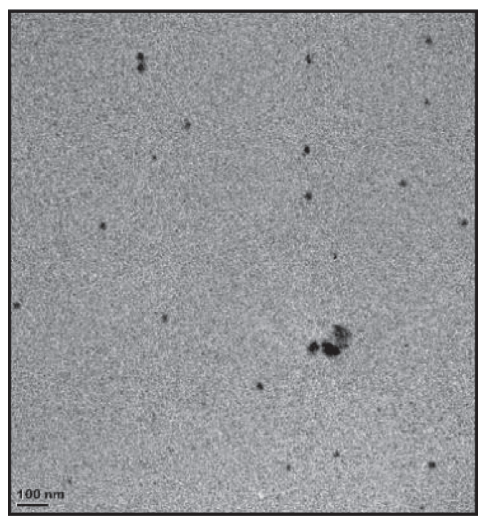

(d)

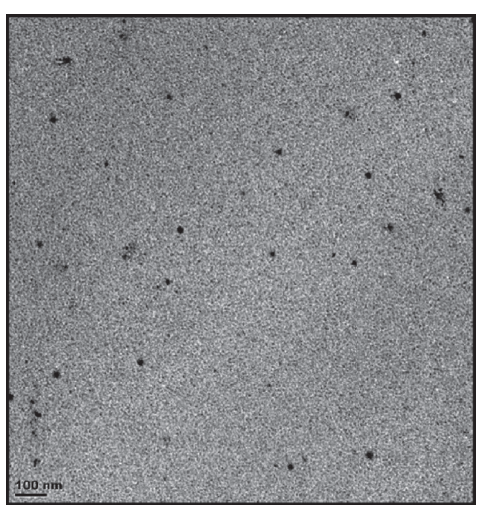

(b)

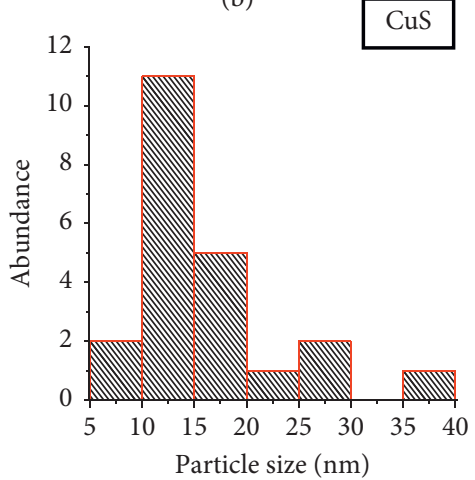

Size distribution

(e)

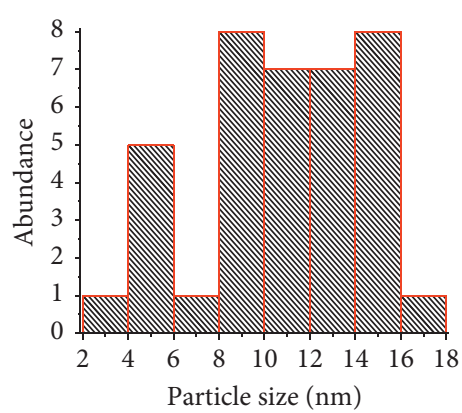

Size distribution

(c)

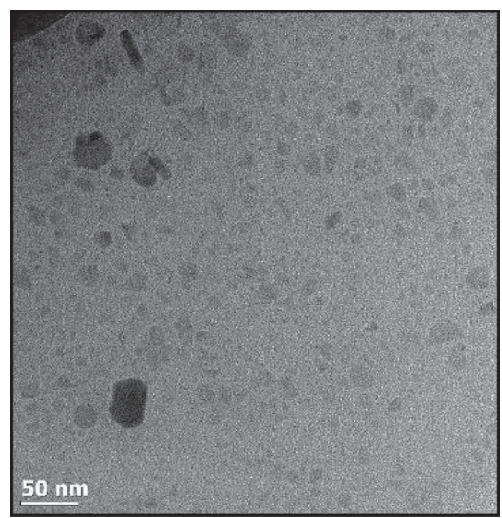

(f)

(b)

FIgURE 2: Continued. 


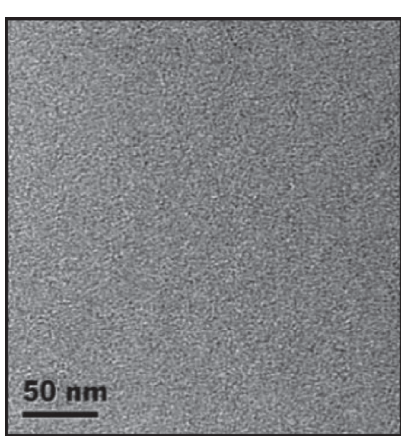

(a)

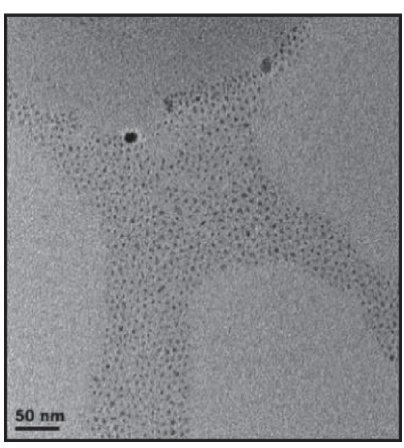

(e)

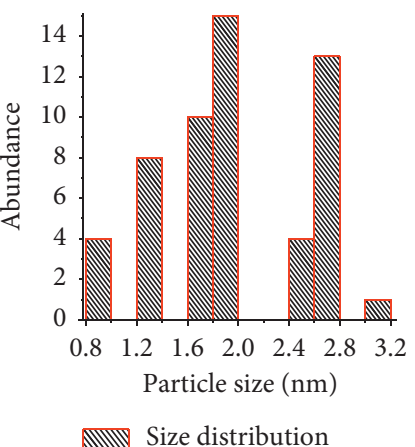

(b)

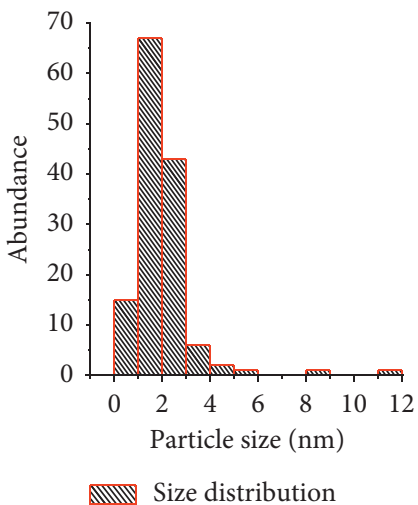

(f)

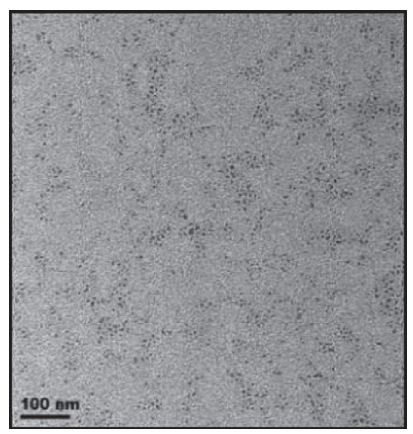

(c)

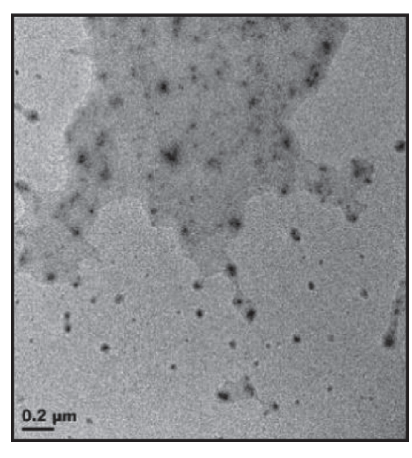

(g)

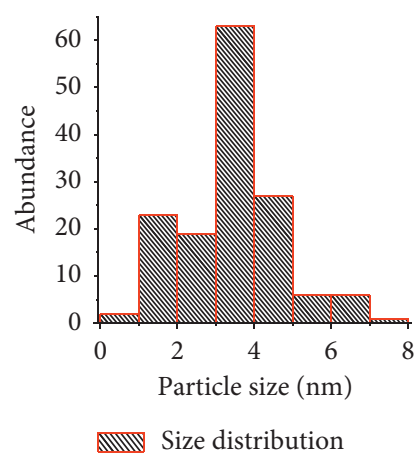

(d)

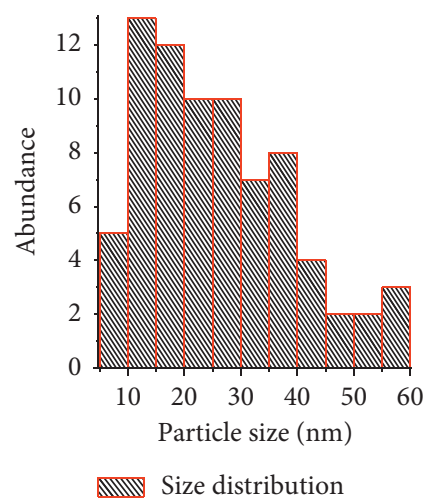

(h)

(c)

FiguRE 2: TEM images and size histograms of copper selenide, copper sulfide, and copper oxide nanoparticles synthesized for $15,30,45$, and $60 \mathrm{~min}$ with their corresponding histogram in OLA at $220^{\circ} \mathrm{C}$ using $1: 1$ mole ratio of $\mathrm{CuO}$.

particle shapes stopped but the particles continued to grow bigger.

Unlike copper selenide, 15 minutes reaction in copper sulfide produced bigger particles that are mixed morphology. The mixed morphologies' included truncated triangles, cube-like structures, and spheres that are overlapping resulting in high agglomeration. When the reaction time was increased to 30,45 , and 60 minutes, a trend of size increase with reaction time was observed just like in copper selenide. This trend corroborates what was predicted by UV/Vis absorption spectroscopy. In both chalcogenides, the material synthesized at 30 minutes produced the smallest particle size than other three materials with shapes that are almost spherical. Copper sulfide nanoparticles synthesized at 45 minutes also produced small particles but with some smaller clusters indicating that these particles were starting to dissolve in one another and forming big particles as Sibokoza et al. [35] and Sibiya et al. [36] reported. This was confirmed by the material synthesized for 60 minutes which revealed that the particles were becoming bigger with time through the Ostwald repining process, and the evolution of shapes was also observed. The small clusters were also observed when Revaprasadu et al. [32] synthesized copper sulfide nanoparticles using the parameters that are given in Table 2. The material that was synthesized for 60 minutes also revealed mixed morphology shapes with hexagonal dominant. This revealed that with longer reaction time, there is evolution of particle shapes, and the shapes of the particles become more defined and well passivized. No agglomeration was observed in copper sulfide nanomaterials that were synthesized for longer reaction time, and this confirmed well distribution of particles that was suggested by their optical properties. A monodispersed population that was observed in copper selenide nanoparticles that were produced at 30 minutes is consistent with its narrower emission peak. The materials synthesized at 30 and 45 minutes gave better optical and structural properties. The materials synthesized for 30 and 45 minutes produced better optical and structural properties in terms of UV/Vis and TEM than other two materials and, therefore, were further studied for their crystallinity and phase composition using XRD since smaller particles are of interest in the antimicrobial study. Copper oxide nanoparticles synthesized for $15,30,45$, and 60 minutes yielded particles of size ranging $0.8-3.2 \mathrm{~nm}$, $0.1-8.0 \mathrm{~nm}, 1-12 \mathrm{~nm}$, and 5-60 nm, respectively. It is evident that 15 minutes reaction produced the smallest particles than those synthesized for longer reaction time.

The particle size of the four materials increased with the reaction time, and this is consistent with literature reports that suggest larger particle size when the nucleation time is 
prolonged [37]. The literature further explains this effect by the Ostwald ripening process, whereby particles group together with smaller ones tending to deposit onto big ones to form larger particles $[38,39]$. The synthesis at 15 and 30 minutes produced uniform sphere-like shapes that are well dispersed without any aggregation observed. The materials prepared at 45 minutes possessed larger particles which can be attributed to the grouping of smaller particles via Ostwald ripening. The particles grew as the synthesis time increased to 60 minutes, and the sphere-like structures were distorted to semisphere-like structures. These results indicate that the effect of time did not only influence the particles size but also the morphology of particles, and this is in consistent with what was reported by Ramasamy et al. [8]. Copper selenide and copper sulfide demonstrated a different behavior when reaction time was investigated. In the synthesis of copper selenide and copper sulfide, 15 minutes gave the largest particles. The trend that is observed in copper oxides was only observed in copper selenide and copper sulfide when the reaction time was increased from 30 minutes to longer reaction times. This confirmed the higher reactivity of oxides than sulfides and selenides.

The XRD patterns of copper selenide nanocrystals synthesized for 30 and $45 \mathrm{~min}$ are shown in Figure 3. The XRD diffraction patterns confirmed that copper selenide nanoparticles were produced in both reaction times with a mixture of phases. The major phase, hexagonal $\mathrm{Cu}_{0.87} \mathrm{Se}$ (klockmannite), is indexed to PDF card no. 04-007-2214 and the minor phase, orthorhombic $\mathrm{CuSe}_{2}$, indexed to PDF card no. 04-004-2178. Impurities of unreacted selenium were observed and indexed to planes (110) and (201) with PDF card no. 01-086-2246. An unidentified impurity was also observed at $79^{\circ}$ and denoted by + .

Figure 4 shows the XRD patterns of the material synthesized for 30 and 45 minutes for copper sulfide nanoparticles. The XRD patterns confirmed the rhombohedral phase $\left(\mathrm{Cu}_{9} \mathrm{~S}_{5}\right.$, digenite with pdf card no. 00-047-1748) at both 30 and 45 minutes of synthesis. Some features of the covellite phase (CuS phase, PDF card no. 04-001-1461) were also detected. The enhanced intensity of diffraction peaks of the material synthesized for 45 minutes predicts high crystallinity of bigger particles compared to those of 30 minutes. The presence of covellite was observed from the absorption feature at 45 minutes of synthesis. Copper selenide observed a mixture of phases with time changes.

The synthesized copper oxide nanoparticles were confirmed by XRD analysis, and their diffraction patters are shown in Figure 5. XRD patterns of copper oxide showed that three of the materials $(15,30$, and 60 minutes) were mostly formed in the cubic $\mathrm{Cu}_{2} \mathrm{O}$ phase (PDF card $n$. 05-0667). At 45 minutes, one characteristics peak was identified as a cubic phase with 220 index.

Figure 5 shows the FTIR spectra of copper selenide, copper sulfide, and copper oxide nanoparticles. Given the shape of the spectra of copper selenide and copper sulfide, it is almost impossible to accurately extract the absorption peaks of the nanoparticles. Copper sulfide and copper oxide nanoparticles spectra produced peaks that were observed approximately at $2845 \mathrm{~cm}^{-1}, 1618 \mathrm{~cm}^{-1}, 1420 \mathrm{~cm}^{-1}$, and
$1582 \mathrm{~cm}^{-1}$ corresponding to - $\mathrm{CH}$ from the alkyl group, $-\mathrm{NH}$ from the alkyl amine group, $-\mathrm{CN}$ from alkyl amine group, and-NH stretching from the amine group, respectively. Copper selenide nanoparticles produced a dark color in solution, and therefore, the peaks produced were not as pronounced as those of copper oxide nanoparticles. All the observed functional groups emerged from the structure of oleylamine [40] as shown in Figure 6.

3.2. Antimicrobial Study. Copper chalcogenide nanoparticles have been suggested for various potential applications, and antimicrobial has been listed among those applications [20]. Disk diffusion and MIC methods have been used to test for the antibacterial and antifungal of the synthesized copper sulfide, copper selenide, and copper oxide nanoparticles. From the copper chalcogenides, $\mathrm{Cu}_{0.87} \mathrm{Se}, \mathrm{Cu}_{9} \mathrm{~S}_{5}$, and $\mathrm{CuO}$ produced best properties and therefore were tested as antibacterial and antifungal (Figures 7 and 8). The bacterial species that were tested are, namely, (1) E. coli which is a Gram-negative, rod-shaped bacterium that is commonly found in the lower intestines of warm-blooded organisms. In 1999, Mead et al. [39] estimated that this organism was responsible for approximately 73000 cases of human illness and 61 deaths per year in the United States; (2) P. aeruginosa which is also a Gramnegative, oxidase-positive, rod that belongs to the family Pseudomonadaceae. This organism is an opportunistic pathogen that causes nosocomial infections, and it can also be found in other environments through the world. $P$. aeruginosa typically infects the pulmonary tract, urinary tract, burns, wounds, and causes blood infections. (3) S. aureus is a Gram-positive bacterium that is a member of the Staphylococcaeceae which causes diseases such as bacteremia, endocarditis, toxic shock syndrome, sepsis, and other metastatic infections; and (4) E. faecalis is also a Grampositive, nonmotile, facultatively anaerobic bacterium inhabiting the gastrointestinal tracts of humans and other mammals. E. faecalis can also cause endocarditis and bacteremia, urinary tract infections, meningitis, and other infections in humans. C. albicans were used for testing the fungal activity of the selected agents. C. albicans are the predominant commensal fungus inhibiting the human oral activity, genitourinary tract, and leads to many Candida infections.

A disk diffusion method was used to determine the sensitivity of the abovementioned microorganisms that were used for antibacterial and antifungal studies with respect to the antimicrobial agents (copper selenide, copper sulfide, and copper oxide). The same procedure that was reported in the previous work conducted by Ntshanka et al. [41] while testing the antimicrobial activity of Combretum molle and Acacia mearnsii plant species was followed. The sensitivity determination was carried out by measuring the inhibition zone which is the area of media where bacteria are unable to grow due to their sensitivity towards the antibacterial agent. A large zone of inhibition is an indication of high sensitivity of bacteria to the antibiotic drug. All three copper chalcogenides nanoparticles that were synthesized were effective 


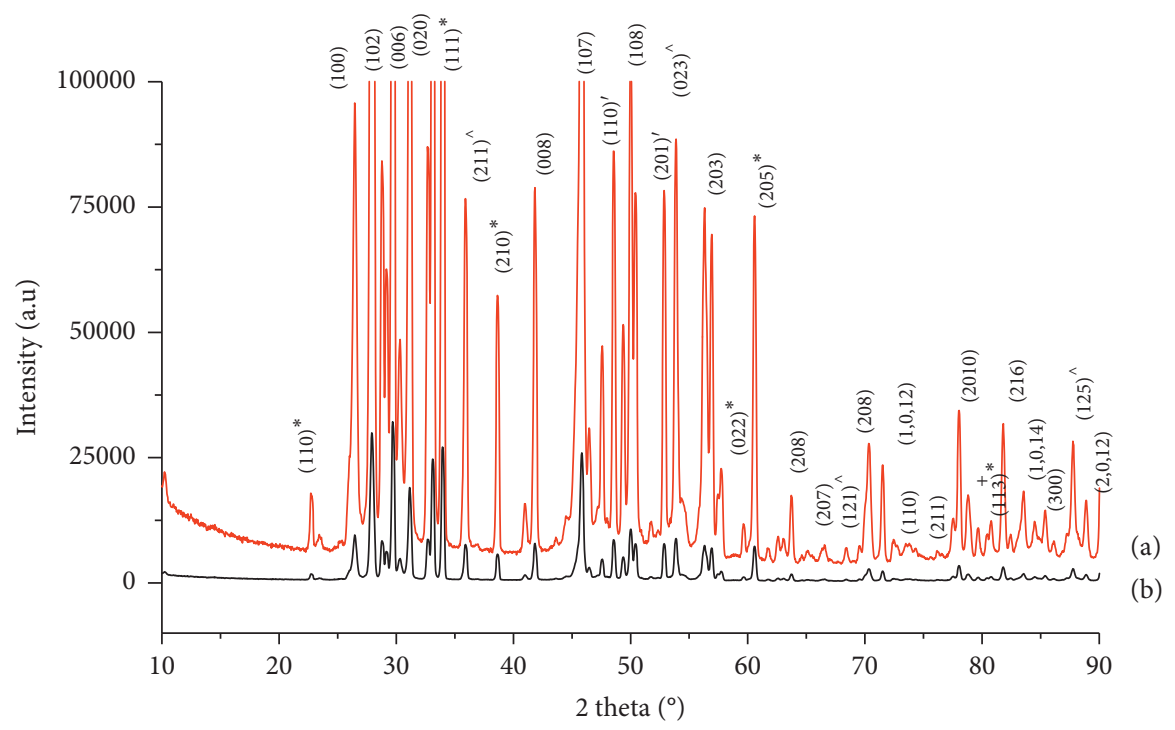

FIGURE 3: XRD patterns of copper selenide nanoparticles synthesized for $30 \mathrm{~min}$ (a) and $45 \mathrm{~min}$ (b) in OLA at $220^{\circ} \mathrm{C}$ using $1: 1$ mole ratio of CuSe.

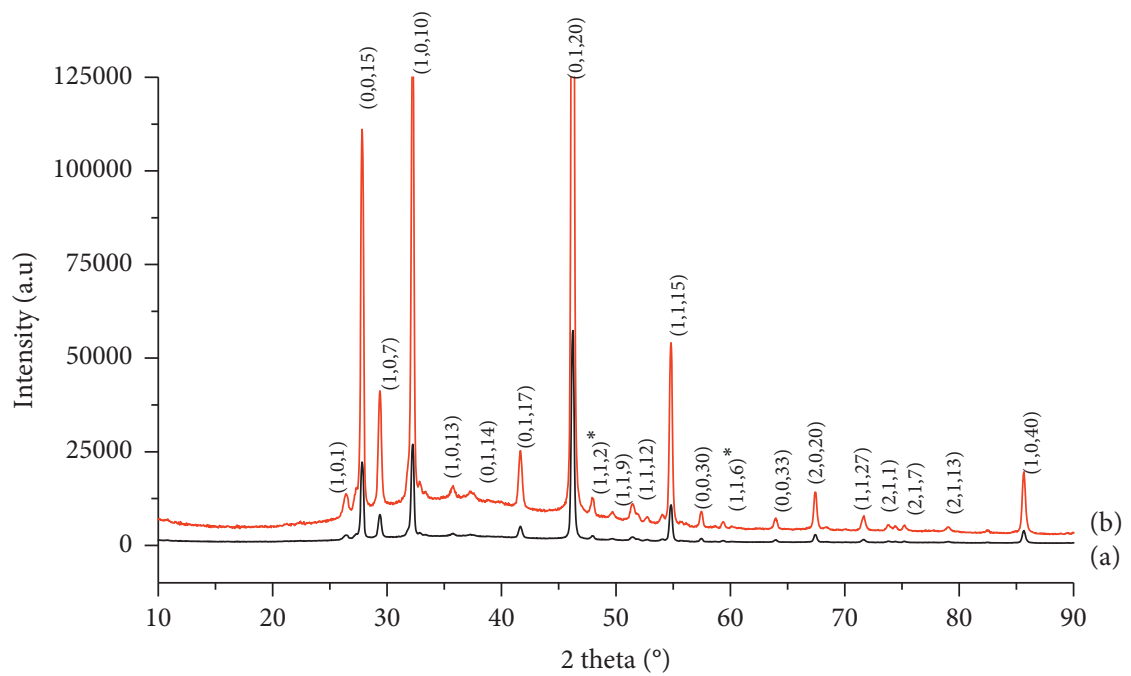

FIGURE 4: XRD patterns of copper sulfide nanoparticles synthesized for $30 \mathrm{~min}$ (a) and $45 \mathrm{~min}$ (b) in OLA at $220^{\circ} \mathrm{C}$ using $1: 1$ mole ratio of $\mathrm{CuS}$.

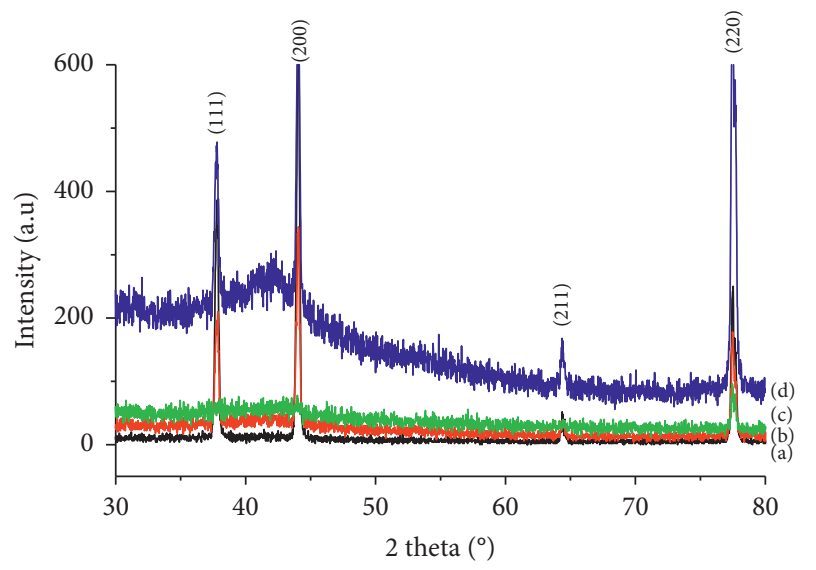

FIGURE 5: XRD patterns of copper oxide nanoparticles synthesized for $15 \mathrm{~min}$ (a), $30 \mathrm{~min}$ (b), $45 \mathrm{~min}$ (c), and $60 \mathrm{~min}$ (d) in OLA at $220^{\circ} \mathrm{C}$ using 1:1 mole ratio of $\mathrm{CuO}$. 


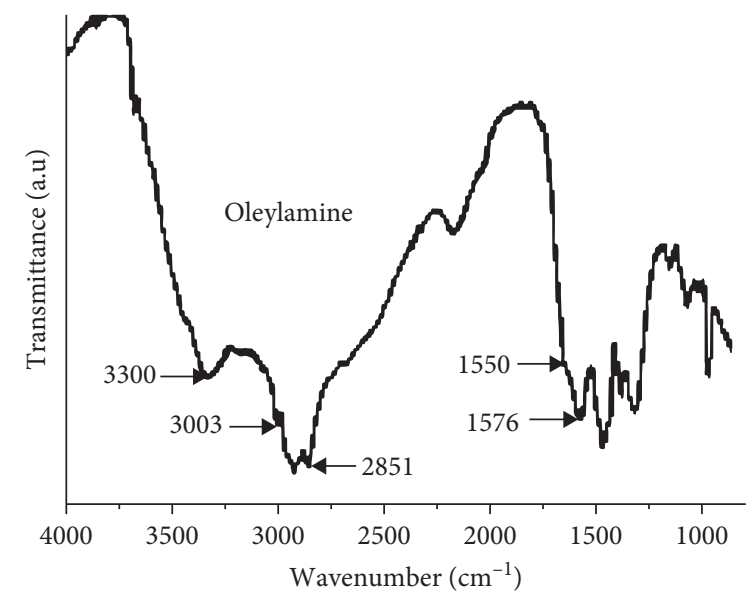

(a)

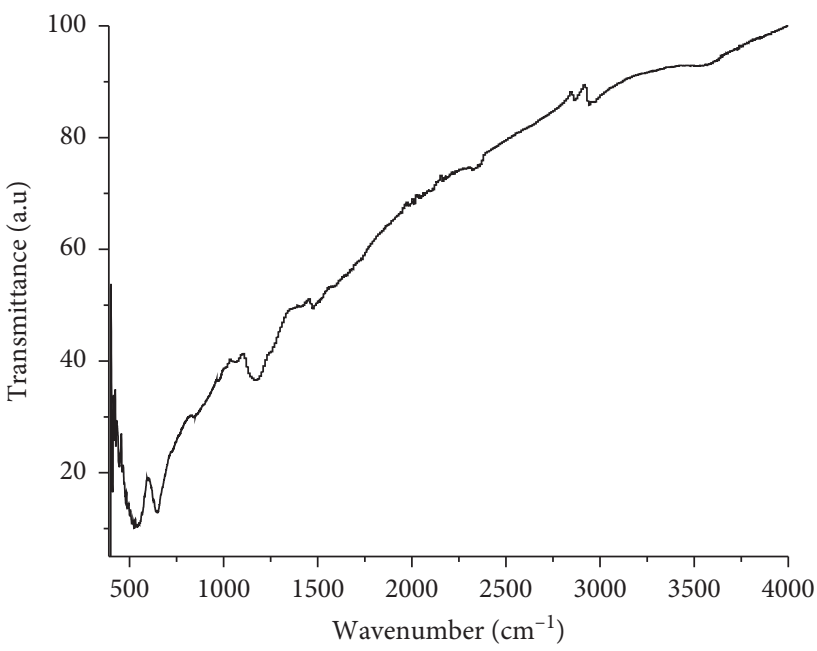

(c)

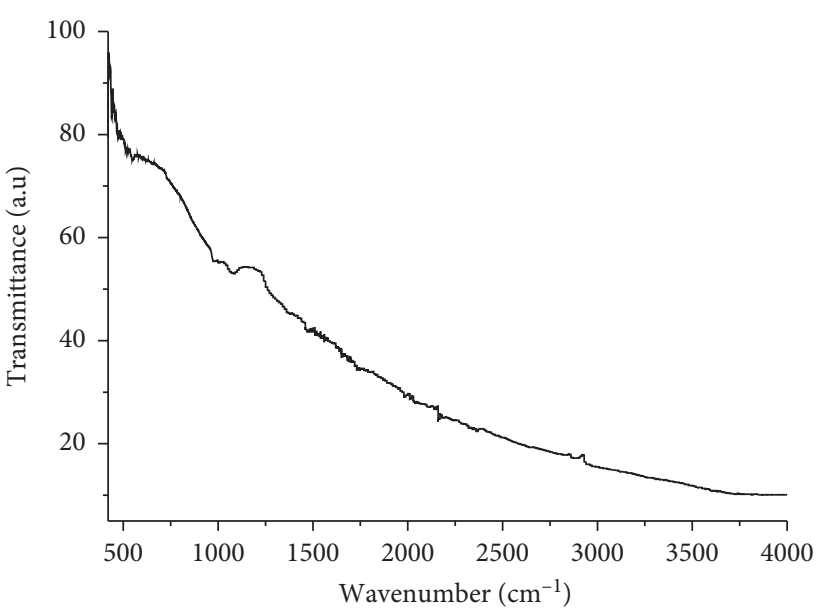

(b)

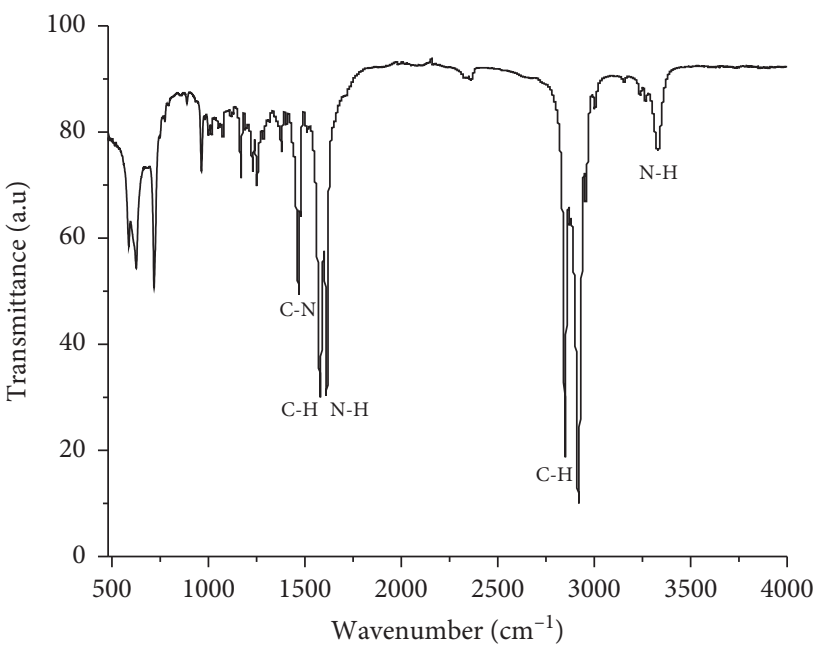

(d)

Figure 6: FTIR spectra of oleylamine (a), copper selenide (b), copper sulfide (c), and copper oxide nanoparticles (d).

towards five microorganisms that were selected for testing as indicated in Table 3 and 4. The antibacterial activity of nanomaterials emerges from at least one of the following mechanisms: (i) inhibition of cell wall/membrane synthesis, (ii) disruption of energy transduction, (iii) production of toxic ROS, (iv) photocatalysis, (v) enzyme inhibition, and (vi) reduced DNA production [42]. The sensitivity of the three copper chalcogenides is attributed to the ability of copper to release $\mathrm{Cu}^{2+}$ ions which have the ability to penetrate and disrupt the cell membrane and biochemical pathway by chelating cellular enzymes DNA damage [43]. Ruparelia et al. [44] suggest that $\mathrm{Cu}$ ions interact with phosphorus and sulfur-containing biomolecules such as DNA and protein to distort their structures and thus disrupt biochemical processes. Chatterjee et al. [45] deduced that the prime effect of copper nanoparticles on microorganisms originates from the oxidation of the metallic $\mathrm{Cu}$ ions which kills the cells by NP-mediated ROS generation in cells. This, therefore, results in cellular lipid peroxidation, protein oxidation, and DNA degradation. In these experimental results, $E$. coli was the most susceptible microorganism with inhibition zone of $28 \mathrm{~mm}$ by copper oxide nanoparticles. $S$. aureus showed more resistance towards copper selenide nanoparticles by giving the smallest inhibition zone of $5 \mathrm{~mm}$ compared to other antibacterial agents. $P$. aeruginosa showed maximal sensitivities towards copper oxide nanoparticles with inhibition zone of $26 \mathrm{~mm}$.

After the screening of the antimicrobial activity, a more accurate and quantitative method (MIC) was used to determine the lowest concentration of the antimicrobial agent to inhibit bacterial activity, and the results are given in Table 4. The results revealed that all the microorganisms that were tested were susceptible to all synthesized nanoparticles. The growth was completely inhibited. Gramnegative (E. coli) revealed to be the most resistant microorganism towards the selected antimicrobial agents. In most cases, higher concentration of the antimicrobial agent was required to inhibit E. coli microorganisms in comparison to other microorganisms especially with copper selenide nanoparticles. Gram-positive S. aureus and $P$. aeruginosa revealed to be more sensitive towards all three copper chalcogenides nanoparticles. E. faecalis showed high 


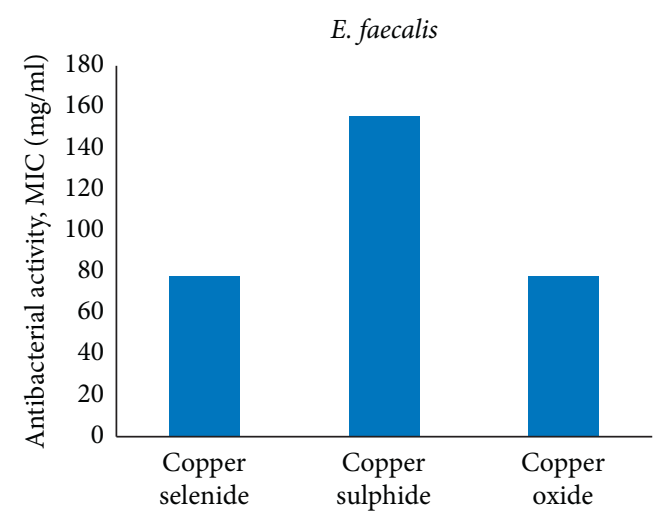

(a)

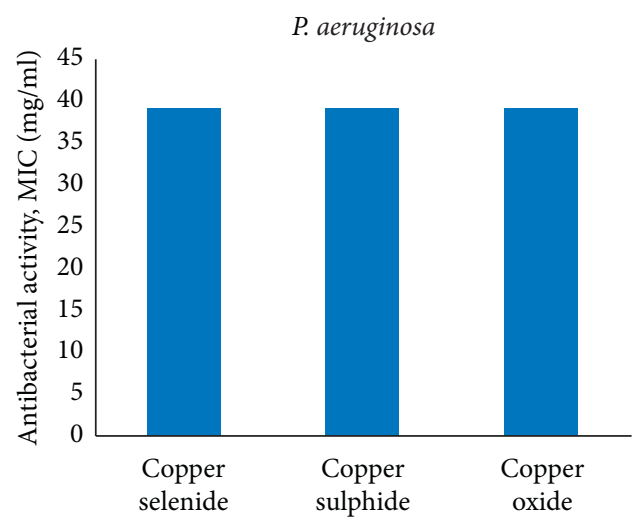

(c)

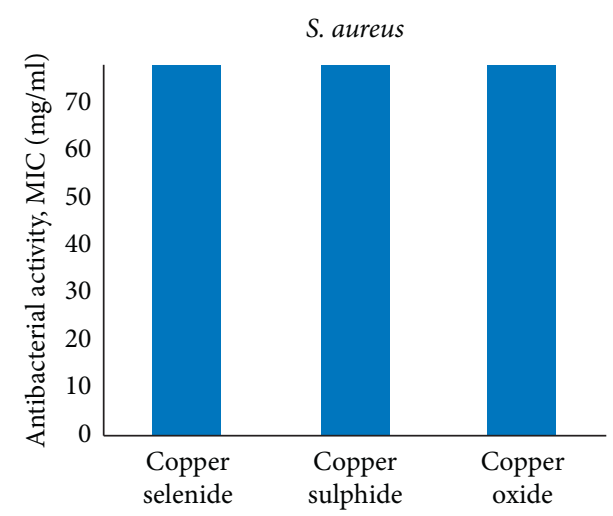

(b)

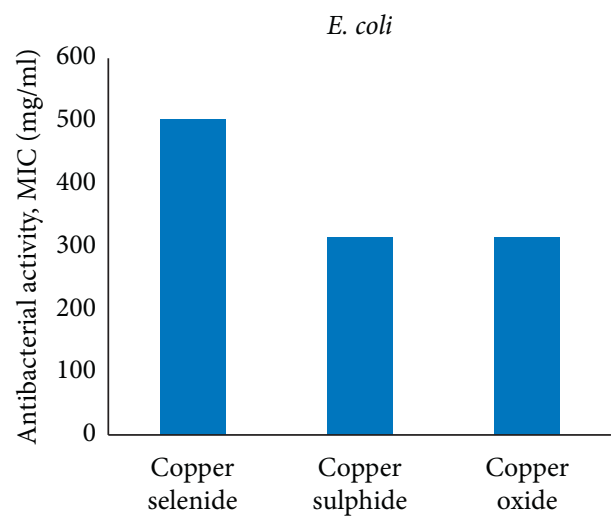

(d)

Figure 7: Antibacterial study of the synthesized copper chalcogenides on E. faecalis, S. aureus, P. aeruginosa, and E. coli.

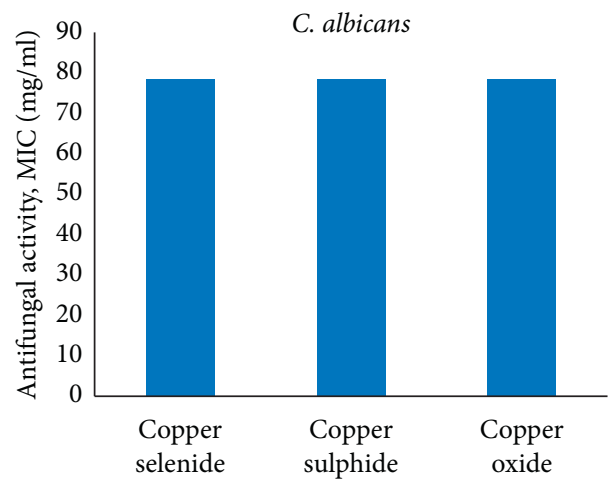

FIgURe 8: Antifungal study of the synthesized copper chalcogenides, C. albicans.

TABLe 3: Agar disk diffusion test for screening the activity of the antimicrobial agents.

\begin{tabular}{|c|c|c|c|c|c|c|}
\hline Antimicrobial agent & $\begin{array}{c}\text { Solvent of } \\
\text { plant extract }\end{array}$ & $\begin{array}{l}\text { E. Faecalis, size of } \\
\text { inhibition }(\mathrm{mm})\end{array}$ & $\begin{array}{l}\text { S. aureus, size of } \\
\text { inhibition }(\mathrm{mm})\end{array}$ & $\begin{array}{l}\text { P. aeruginosa, size } \\
\text { of inhibition }(\mathrm{mm})\end{array}$ & $\begin{array}{c}\text { E. coli, size of } \\
\text { inhibition }(\mathrm{mm})\end{array}$ & $\begin{array}{l}\text { C. albicans, size of } \\
\text { inhibition }(\mathrm{mm})\end{array}$ \\
\hline $\mathrm{CuSe}$ & Ethanol & 12 & 5 & 12 & 14 & 6 \\
\hline $\mathrm{CuS}$ & Ethanol & 8 & 9 & 24 & 25 & 5 \\
\hline $\mathrm{CuO}$ & Ethanol & 12 & 13 & 26 & 28 & 12 \\
\hline
\end{tabular}

resistance towards copper sulfide nanoparticles. C. albicans showed high sensitivity towards all three copper chalcogenides nanoparticles. Amongst all three copper chalcogenides nanoparticles that were tested, copper oxide showed higher sensitivity towards all five microorganisms in comparison to copper selenide and copper sulfide. It 
TABle 4: Determination of minimum inhibitory concentrations (MICs) of antimicrobial agents by broth dilution.

\begin{tabular}{lcccccc}
\hline $\begin{array}{l}\text { Antimicrobial } \\
\text { agent }\end{array}$ & $\begin{array}{c}\text { Solvent of plant } \\
\text { extract }\end{array}$ & $\begin{array}{c}\text { E. faecalis, MIC } \\
(\mathrm{mg} / \mu \mathrm{l})\end{array}$ & $\begin{array}{c}\text { S. aureus, } \\
\mathrm{MIC}(\mathrm{mg} / \mu \mathrm{l})\end{array}$ & $\begin{array}{c}\text { P. aeruginosa, } \\
\text { MIC }(\mathrm{mg} / \mu \mathrm{l})\end{array}$ & $\begin{array}{c}\text { E. coli, MIC } \\
(\mathrm{mg} / \mu \mathrm{l})\end{array}$ & $\begin{array}{c}\text { C. albicans, } \\
\mathrm{MIC}(\mathrm{mg} / \mu \mathrm{l})\end{array}$ \\
\hline $\mathrm{CuSe}$ & Ethanol & 78.13 & 78.13 & 39.06 & 5000 & 78.13 \\
$\mathrm{CuS}$ & Ethanol & 156.25 & 78.13 & 39.06 & 312.5 & 78.13 \\
$\mathrm{CuO}$ & Ethanol & 78.12 & 78.13 & 39.06 & 312.5 & 78.13 \\
\hline
\end{tabular}

TABLE 5: Antimicrobial activity of the synthesized copper chalcogenides in comparison with previously published data.

\begin{tabular}{|c|c|c|c|c|c|c|c|c|c|}
\hline \multicolumn{10}{|c|}{ Zone of inhibition $(\mathrm{mm})$ and/MIC $(\mathrm{mg} / \mathrm{mL})$} \\
\hline \multirow{2}{*}{$\begin{array}{l}\text { Bacterial } \\
\text { strains } \\
\text { Synthesized } \\
\text { NPs }\end{array}$} & \multicolumn{2}{|c|}{ Enterococcus faecalis } & \multicolumn{2}{|c|}{ Staphylococcus aureus } & \multicolumn{2}{|c|}{ Pseudomonas aeruginosa } & \multicolumn{2}{|c|}{ Enterococcus coli } & \multirow{2}{*}{ References } \\
\hline & $\begin{array}{c}\text { Results } \\
\text { obtained }\end{array}$ & Literature & $\begin{array}{c}\text { Results } \\
\text { obtained }\end{array}$ & Literature & $\begin{array}{c}\text { Results } \\
\text { obtained }\end{array}$ & Literature & $\begin{array}{c}\text { Results } \\
\text { obtained }\end{array}$ & Literature & \\
\hline CuSe & $12 \mathrm{~mm}$ & - & $5 \mathrm{~mm}$ & - & $12 \mathrm{~mm}$ & - & $14 \mathrm{~mm}$ & - & - \\
\hline $\mathrm{CuS}$ & $\begin{array}{c}8 \mathrm{~nm} \text { and } \\
0.16 \mathrm{mg} / \mathrm{mL}\end{array}$ & $0.39 \mathrm{mg} / \mathrm{mL}$ & $\begin{array}{c}9 \mathrm{~nm} \text { and } \\
0.08 \mathrm{mg} / \mathrm{mL}\end{array}$ & $<0.05 \mathrm{mg} / \mathrm{mL}$ & $\begin{array}{c}24 \mathrm{~nm} \text { and } \\
0.04 \mathrm{mg} / \mathrm{mL}\end{array}$ & $3.125 \mathrm{mg} / \mathrm{mL}$ & $\begin{array}{c}25 \mathrm{~nm} \text { and } \\
0.31 \mathrm{mg} / \mathrm{mL}\end{array}$ & - & Mofokeng [43] \\
\hline $\mathrm{CuO}$ & $12 \mathrm{~mm}$ & _ & $13 \mathrm{~mm}$ & $22 \mathrm{~mm}$ & $26 \mathrm{~mm}$ & $21 \mathrm{~mm}$ & $28 \mathrm{~mm}$ & $20 \mathrm{~mm}$ & Azam [33] \\
\hline
\end{tabular}

produced highest inhibition zones and required lowest minimum inhibitory concentrations to inhibit growth. The increased sensitivity is associated with high reactivity of oxygen which is due to its smaller size. Copper selenide nanoparticles demonstrated the least sensitivity towards all the pathogens that were tested. Table 5 provides the activity of the three copper chalcogenides with at least one data from research that has been previously reported. The findings of this work are in line with the results that are previously reported; however, the data from copper selenide nanoparticles are very limited, and this could be due to its low antimicrobial activity towards microorganisms; hence, not much has been performed on its antimicrobial study.

\section{Conclusion}

The investigation of reaction time revealed that the particle size increases with longer reaction time and there is evolution of particle shapes. The shapes of the particles become more defined and well passivized at prolonged times. Amongst the three chalcogenides that were synthesized, copper oxide nanoparticles behaved differently from the selenide and sulfide nanoparticles, and this is attributed to its high reactivity in relation to the atomic size. With regards to physical and chemical properties of copper selenide and copper sulfide nanoparticles, 30 minutes reaction time gave the best optimal time as compared to 15 minutes for copper oxide nanoparticles. The antibacterial study revealed that all the microorganisms tested were susceptible to all three copper chalcogenide nanoparticles. Copper oxide showed a higher sensitivity towards both Gram-negative and Grampositive bacteria and fungi compared to the two chalcogenides ( $\mathrm{CuSe} / \mathrm{CuS})$, and copper selenide showed the least sensitivity against all bacteria and fungi tested. This confirms its less reactivity compared to copper sulfide and copper oxide nanoparticles. Over all the information about the antimicrobial activity of copper selenide nanoparticles is very limited, and this could be due to its low sensitivity towards microorganisms.

\section{Data Availability}

The data used to support the findings of this study are included within the article.

\section{Conflicts of Interest}

The authors declare that they have no conflicts of interest.

\section{Acknowledgments}

The authors would like to thank Vaal University of Technology department of chemistry for funding, laboratory support, and research infrastructure used for carrying out the research work.

\section{References}

[1] D. Dorfs, T. Härtling, K. Miszta et al., "Reversible tunability of the near-infrared valence band plasmon resonance in $\mathrm{Cu} 2-\mathrm{xSe}$ nanocrystals," Journal of the American Chemical Society, vol. 133, no. 29, pp. 11175-11180, 2011.

[2] A. Pallet and K. Hand, "Complicated urinary tract infections: practical solutions for the treatment of multi-resistant Gramnegative bacteria," Journal of Antimicrobial Chemotherapy, vol. 52, pp. 25-33, 2010.

[3] V. Chintamunnee and M. F. Mahomoodally, "Herbal medicine commonly used against non-communicable diseases in the tropical island of Mauritius," Journal of Herbal Medicine, vol. 2, no. 4, pp. 113-125, 2012.

[4] D. F. Williams, "On the mechanisms of biocompatibility," Biomaterials, vol. 29, no. 20, pp. 2941-2953, 2008.

[5] M. P. Kalenga, S. Govindraju, M. Airo, M. J. Moloto, L. M. Sikhwivhilu, and N. Moloto, "Size quantization in Cu2Se nanocrystals," Optical Materials, vol. 38, pp. 310-313, 2014.

[6] K. L. K. L. Hung, X. G. Li, S. Q. Liu, N. Tan, and L. Q. Chen, "Research progress of vanadium redox flow battery for energy storage in China," Renewable Energy, vol. 33, pp. 186-192, 2008.

[7] T. M. D. Dang, T. T. T. Le, E. Fribourg-Blanc, and M. C. Dang, "Synthesis and optical properties of copper nanoparticles 
prepared by a chemical reduction method," Advances in Natural Sciences: Nanoscience and Nanotechnology, vol. 2, no. 1, Article ID 015009, 2011.

[8] K. Ramasamy, W. Maneerprakorn, M. A. Malik, and P. O'Brien, "Single-molecule precursor-based approaches to cobalt sulphide nanostructures," Philosophical Transactions of the Royal Society A: Mathematical, Physical and Engineering Sciences, vol. 368, no. 1927, pp. 4249-4260, 2010.

[9] C. B. Murray, D. J. Norris, and M. G. Bawendi, "Synthesis and characterization of nearly monodisperse CdE ( $\mathrm{E}=$ sulfur, selenium, tellurium) semiconductor nanocrystallites," Journal of the American Chemical Society, vol. 115, Article ID 87068715, 1993.

[10] W. Li, R. Zamani, P. Rivera Gil et al., "CuTe nanocrystals: shape and size control, plasmonic properties, and use as SERS probes and photothermal agents," Journal of the American Chemical Society, vol. 135, no. 19, pp. 7098-7101, 2013.

[11] N. G. Mbewana-Ntshanka, M. J. Moloto, and P. K. Mubiayi, "Role of mine and phosphine groups in oleylamine and trioctylaosphine in the synthesis of copper chalcogenide nanoparticles," Heliyon, vol. 6, Article ID 05130, 2020.

[12] M. Suleiman, M. Maousa, A. Hussein, B. Hammouti, T. B. Hadda, and L. Warad, "Copper (II)-Oxide nanostructures: synthesis, characterizations and their applications-review," Journal of Materials and Environmental Science, vol. 4, pp. 792-797, 2013.

[13] Y. Aparna, K. R. Venkateswara, and S. P. Srinivasa, "Preparation and characterization of $\mathrm{CuO}$ nanoparticles by novel sol-gel technique," Journal of Nano- and Electronic Physics, vol. 4, no. 3005, pp. 1-4, 2012.

[14] W.-T. Yao, S.-H. Yu, Y. Zhou et al., "formation of uniform $\mathrm{CuO}$ nanorods by spontaneous aggregation: selective synthesis of $\mathrm{CuO}, \mathrm{Cu} 2 \mathrm{O}$, and $\mathrm{Cu}$ nanoparticles by a Solid-Liquid phase Arc discharge process," The Journal of Physical Chemistry B, vol. 109, no. 29, pp. 14011-14016, 2005.

[15] D. I. Son, C. H. You, and T. W. Kim, "Structural, optical, and electronic properties of colloidal $\mathrm{CuO}$ nanoparticles formed by using a colloid-thermal synthesis process," Applied Surface Science, vol. 255, no. 21, pp. 8794-8797, 2009.

[16] Y. Lim, J. Choi, and T. Hanrath, "Facile synthesis of colloidal $\mathrm{CuO}$ nanocrystals for light harvesting applications," Journal of Nanomaterials, vol. 4, pp. 217-225, 2012.

[17] E. Darezershki, M. Alizadeh, M. Bakhtiari, M. Schaffie, and M. Ranjbar, "A novel thermal decomposition method for the synthesis of $\mathrm{ZnO}$ nanoparticles from low concentration $\mathrm{ZnSO}_{4}$ solutions," Applied Clay Science, vol. 54, pp. 107-111, 2011.

[18] W. Narongdet, C. Piyanut, V. Naratip, and P. Wisanu, "Sonochemical synthesis and characterization of copper oxide nanoparticles," Energy Procedia, vol. 29, pp. 404-409, 2011.

[19] H. Wang, J.-J. Zhu, J.-M. Zhu, and H.-Y. Chen, "Sonochemical method for the preparation of bismuth sulfide nanorods," The Journal of Physical Chemistry B, vol. 106, no. 15, pp. 3848-3854, 2002.

[20] S. Honary, H. Barabadi, E. Gharaeifathabad, and F. Naghibi, "Green synthesis of copper oxide nanoparticles using penicillium aurantiogriseum, penicillium citrinum and penicillium waksmanii," Digest Journal of Nanomaterials and Biostructures, vol. 7, pp. 999-1005, 2012.

[21] P. H. C. Camargo, T. S. Rodrigues, A. G. M. Da Silva, and J. Wang, "Controlled synthesis: nucleation and growth in solution," Metallic Nanostructures, vol. 301, p. 196, 2015.
[22] A. Syed, "Future medicine: nanomedicine," Journal of International Medical Science Academy, vol. 25, pp. 187-192, 2012.

[23] Z. Tachan, M. Shalom, I. Hod, S. Rühle, S. Tirosh, and A. Zaban, "PbS as a highly catalytic counter electrode for polysulfide-based quantum dot solar cells," The Journal of Physical Chemistry C, vol. 115, no. 13, pp. 6162-6166, 2011.

[24] Y. Xiong, B. Wiley, J. Chen, Z.-Y. Li, Y. Yin, and Y. Xia, "Corrosion-based synthesis of single-crystal Pd nanoboxes and nanocages and their surface plasmon properties," Angewandte Chemie, vol. 117, no. 48, pp. 8127-8131, 2005.

[25] P. Gupta and M. Ramrakhiani, "Influence of the particle size on the optical properties of CdSe nanoparticles," The Open Nanoscience Journal, vol. 3, no. 1, pp. 15-19, 2009.

[26] J. Hu, L.-S. Li, W. Yang, L. Manna, L.-W. Wang, and A. P. Alivisatos, "Linearly polarized emission from colloidal semiconductor quantum rods," Science, vol. 292, pp. 20602063, 2000.

[27] A. M. Smith and S. Nie, "Semiconductor nanocrystals: structure, properties, and band gap engineering," Accounts of Chemical Research, vol. 43, no. 2, pp. 190-200, 2010.

[28] C. S. Ravi, P. S. Manmeet, S. K. Onkar, and S. C. Paramdeep, "Influence of synthesis and calcination temperatures on particle size and ethanol sensing behavior of chemically synthesized $\mathrm{SnO} 2$ nanostructures," Sensors and Actuators B: Chemical, vol. 143, pp. 226-232, 2009.

[29] N. Moloto, N. Revaprasadu, P. L. Musetha, and M. J. Moloto, "The effect of precursor concentration, temperature and capping group on the morphology of CdS nanoparticles," Journal of Nanoscience and Nanotechnology, vol. 10, pp. 219-223, 2012/2009.

[30] J. Cheon, Y. Jun, and J. Choi, "Shape control of semiconductor and metal oxide nanocrystals through nonhydrolytic colloidal routes," Angewandte Chemie International Edition English, vol. 45, pp. 3414-3439, 2006.

[31] M. P. Kalenga, N. Molot, M. J. Moloto, and Sikhwivhilu, "Time effect on the conventional colloidal synthesis of copper selenide nanocrystals," in Proceedings of the Researchgate, 57th Annual Conference of South African Institute of Physics, Johannesburg, South Africa, May 2012.

[32] N. Revaprasadu, N. A. Malik, and P. O'Brien, "Synthesis of TOPO-capped nanocrystals of copper sulphide from a singlesource precursor, [Cu (S2CNMe (nHex)) 2]," South African Journal of Chemistry, vol. 57, pp. 40-43, 2004.

[33] A. Azam, S. A. Ahmed, M. Oves, M. S. Khan, and A. Memic, "Size-dependent antimicrobial properties of $\mathrm{CuO}$ nanoparticles against Gram-positive and -negative bacterial strains," International Journal of Nanomedicine, vol. 7, pp. 3527-3535, 2012.

[34] N. Moloto, M. J. Moloto, N. J. Coville, and S. Sinha Ray, "Synthesis and characterization of nickel selenide nanoparticles: size and shape determining parameters," Journal of Crystal Growth, vol. 324, no. 1, pp. 41-52, 2011.

[35] S. B. Sibokoza, M. J. Moloto, N. Moloto, and P. N. Sibiya, "The effect of and precursor concentration on the synthesis of cobalt sulphide nanoparticles using cobalt diethyldithiocarbamate complex," Chalcogenide Letters, vol. 14, pp. 68-78, 2017.

[36] N. P. Sibiya and M. J. Moloto, "Effect of precursor concentration and $\mathrm{pH}$ on the shape and size of starch capped silver selenide (Ag2Se) nanoparticles," Chalcogenide Letters, vol. 11, pp. 577-588, 2014. 
[37] W. Ostwald, "Blocking of Ostwald ripening allowing longterm stabilization," Zeitschrift für Physikalische Chemie, vol. 37, p. 385, 1901.

[38] P. W. Voorhees, "The theory of Ostwald ripening," Journal of Statistical Physics, vol. 38, no. 1-2, pp. 231-252, 1985.

[39] P. S. Mead, L. Slutsker, V. Dietz et al., "Food-related illness and death in the United States," Emerging Infectious Diseases, vol. 5, no. 5, pp. 607-625, 1999.

[40] I. O. Perez De Berti, M. V. Cagnoli1, G. Pecchi et al., "Alternative low-cost approach to the synthesis of magnetic iron oxide nanoparticles by thermal decomposition of organic precursors," Nanotechnology, vol. 24, p. 11, Article ID $175601 p, 2013$.

[41] N. M. Ntshanka, I. Ejidike, F. Mtunzi, and M. J. Moloto, "Investigation into phytochemical profile, antioxidant and antibacterial potentials of Combretum molle and Acacia mearnsii leaf parts," Biomedical and Pharmacology Journal, vol. 13, pp. 1683-1694, 2020.

[42] E. Weir, A. Lawlor, A. Whelan, and F. Regan, "The use of nanoparticles in anti-microbial materials and their characterization," The Analyst, vol. 133, no. 7, pp. 835-845, 2008.

[43] T. P. Mofokeng, M. J. Moloto, P. M. Shumbula et al., "Antimicrobial activity of amino acid-capped zinc and copper sulphide nanoparticles," Journal of Nanotechnology, vol. 9, 2018.

[44] J. P. Ruparelia, A. K. Chatterjee, S. P. Duttagupta, and S. Mukherji, "Strain specificity in antimicrobial activity of silver and copper nanoparticles," Acta Biomaterialia, vol. 4, no. 3, pp. 707-716, 2008.

[45] A. K. Chatterjee and R. Chakraborty, "Mechanism of antibacterial activity of copper nanoparticles," Nanotechnology, vol. 25, p. 12, Article ID 135101, 2014. 